\title{
Myocardial infarction and generalised anxiety disorder: 10-year follow-up
}

Annelieke M. Roest, Marij Zuidersma and Peter de Jonge

\section{Background}

Few studies have addressed the relationship between generalised anxiety disorder and cardiovascular prognosis using a diagnostic interview.

\section{Aims}

To assess the association between generalised anxiety disorder and adverse outcomes in patients with myocardial infarction.

\section{Method}

Patients with acute myocardial infarction $(n=438)$ were recruited between 1997 and 2000 and were followed up until 2007. Current generalised anxiety disorder and postmyocardial infarction depression were assessed with the composite International Diagnostic Interview. The end-point consisted of all-cause mortality and cardiovascular-related readmissions.

\section{Results}

During the follow-up period, 198 patients had an adverse event. Generalised anxiety disorder was associated with an increased rate of adverse events after adjustment for age and gender (hazard ratio: 1.94; 95\% confidence interval: 1.14-3.30; $P=0.01$ ). Additional adjustment for measures of cardiac disease severity and depression did not change the results.

\section{Conclusions}

Generalised anxiety disorder was associated with an almost twofold increased risk of adverse outcomes independent demographic and clinical variables and depression.

\section{Declaration of interest}

None.
During the past decades, substantial research has focused on the association between psychological distress and morbidity and mortality. Most studies have focused on the role of depression with coronary heart disease. Several meta-analyses indicate that depression is a risk factor for the development of coronary heart disease in the general population ${ }^{1-3}$ and is associated with cardiovascular events and mortality in patients with coronary heart disease. ${ }^{3-6}$

Less research has focused on the role of anxiety. A recent meta-analysis showed that symptoms of anxiety were associated with a $26 \%$ increased risk of incident coronary heart disease. ${ }^{7}$ Anxiety disorders have been associated with the development of coronary heart disease in younger men, ${ }^{8}$ and with all-cause mortality in an older male population. ${ }^{9}$ The results for generalised anxiety disorder are inconsistent. Generalised anxiety disorder has been shown to be related to all-cause mortality in a veteran population. ${ }^{10}$ However, in a community sample of older persons, generalised anxiety disorder did not increase the risk of death. ${ }^{11}$

In patients with acute myocardial infarction, the prevalence of elevated symptoms of anxiety is on average $30 \% .^{12}$ In a metaanalysis including 12 studies covering 5750 patients with myocardial infarction, it was shown that anxiety was associated with a $36 \%$ increased risk of new cardiovascular events or mortality. ${ }^{12}$ A significant limitation of the studies focusing on the relationship between anxiety and impaired prognosis in patients with myocardial infarction conducted thus far is that most have used questionnaires to assess the presence of elevated symptoms of anxiety. Although questionnaires can be used as screening tools, ${ }^{13-16}$ they are not sufficient to diagnose an anxiety disorder. Furthermore, questionnaires are inadequate in distinguishing between emotional disorders, specifically between anxiety and depression. ${ }^{13,17,18}$ To our knowledge, only three studies have assessed the association between generalised anxiety disorder assessed with a diagnostic interview and adverse cardiovascular prognosis. Two of these studies were in patients with (stable) coronary heart disease and found significant associations between generalised anxiety disorder and cardiovascular events. ${ }^{13,19}$ In contrast, the third study concluded that acute coronary syndrome patients with a lifetime diagnosis of generalised anxiety disorder tended to experience a better cardiac prognosis. ${ }^{20}$

To date no study has assessed the prognostic impact of a diagnosis of current generalised anxiety disorder after acute myocardial infarction. Therefore, we evaluated the prognostic impact of generalised anxiety disorder after myocardial infarction on new cardiovascular events and mortality up until 10 years after the myocardial infarction using a formal diagnostic interview. As generalised anxiety disorder and depression are closely associated, ${ }^{21-23}$ we specifically analysed whether its impact is independent from depression.

\section{Method}

\section{Patients}

Patients were included from the Depression after Myocardial Infarction (DepreMI) study. This was a naturalistic cohort study evaluating the effects of depression after myocardial infarction on adverse cardiovascular outcomes. Details of this study are described elsewhere. ${ }^{24,25}$ Previous publications on DepreMI have all focused on the association between depression and cardiac disease. ${ }^{24-28}$ These studies found a significant association between depressive symptoms and incident depressive episodes with cardiovascular events after a 2.5 -year follow-up period. ${ }^{26-28}$ The impact of anxiety on cardiovascular outcomes has not been examined before. Eligible patients admitted consecutively for myocardial infarction at four hospitals in The Netherlands between September 1997 and September 2000 were asked to participate. At least two of the following three criteria for myocardial infarction had to be met: (1) a documented increase in cardiac enzyme levels; (2) typical electrocardiographic changes; and (3) at least $20 \mathrm{~min}$ of chest pain. Exclusion criteria were the 
presence of another somatic disease likely to influence short-term survival, myocardial infarction during hospital admission for another reason (except unstable angina), and being unable to participate in study procedures. The institutional review board of each participating hospital approved the protocol and all participants signed informed consent.

\section{Assessment of generalised anxiety disorder}

Generalised anxiety disorder is characterised by a period of at least 6 months with prominent tension, worry and feelings of apprehension about everyday events and problems. Associated symptoms are of autonomic arousal and other somatic or cognitive symptoms of tension and worry. ${ }^{29}$ The presence of an ICD-10 diagnosis of current generalised anxiety disorder was assessed by means of the Composite International Diagnostic Interview (CIDI) version 1.1, ${ }^{30}$ which was administered 3 months post-myocardial infarction in order to reduce possible confounding in the period immediately after the myocardial infarction.

\section{Assessment of the covariates}

Age, gender, clinical characteristics, cardiac risk factors and comorbidities were assessed during hospitalisation for the index myocardial infarction and from hospital charts. Left ventricular ejection fraction (LVEF) was assessed by echocardiography, radionuclide ventriculography, gated single photon emission computed tomography, magnetic resonance imaging, angiography or clinical assessment. Living alone and level of education were assessed in an interview 3 months after the myocardial infarction. The presence of an ICD-10 diagnosis of a post-myocardial infarction depressive episode was assessed with the CIDI at 3 months after the myocardial infarction.

\section{Assessment of adverse outcomes}

Data concerning mortality were obtained up until 31 December 2007 from the Dutch Central Bureau of Statistics by linkage to the municipal personal records database. Data concerning hospital admissions in the period between the index myocardial infarction and 31 December 2007 came from the Dutch national registry of hospital discharges and were obtained from the Dutch Central Bureau of Statistics by linkage to the municipal personal records database. Hospital readmissions with ICD-9 codes 410, 411, 413, 414 (ischemic heart disease); 427.1, 427.4, 427.5 (cardiac arrhythmia); 428, 398.91, 402.01, 402.11, 402.91, 404.01, 404.03, $404.11,404.13,404.91,404.93$ (heart failure); 433, 434, 435, 437.0, 437.1 (cerebrovascular disease); and 440, 443.9 (peripheral vascular disease) were included as cardiovascular events. We included these events to be consistent with previous publications on this cohort. ${ }^{26-28}$ The primary end-point of this study was a combined end-point of cardiovascular events and all-cause mortality. The follow-up period for adverse outcomes started at the CIDI interview at 3 months after the myocardial infarction and ended on 31 December 2007. This time frame was chosen to optimise the number of potential events. Only deaths and cardiovascular-related readmissions occurring between the CIDI interview at 3 months after the myocardial infarction and 31 December 2007 were considered as adverse outcomes.

\section{Statistical analyses}

Baseline demographic and clinical characteristics were compared with chi-squared and Student's $t$-test. For this purpose, nonnormally distributed continuous variables were log-transformed. We calculated event-free survival time as time to first event or death. If no event or death occurred, the patient was censored at 31 December 2007. Using Cox regression we evaluated whether event-free survival was different for patients with and patients without generalised anxiety disorder after the myocardial infarction. In the basic model, adjustments were made for age and gender. Additionally, we adjusted for LVEF and diagnosis of post-myocardial infarction depression, because these have been shown to be associated with worse cardiovascular prognosis. In sensitivity analyses, adjustments were made for other clinical variables that significantly predicted cardiovascular events and mortality in the present sample, namely anterior site of the index myocardial infarction, and history of myocardial infarction and peripheral vascular disease. For all analyses, SPSS 14 for Windows was used and significance level was set at 0.05 , two-tailed.

\section{Results}

For this study, 1166 patients were assessed for eligibility. Of these, 882 patients were eligible, of whom 528 (59.9\%) signed an informed consent. Of the 461 patients with a CIDI interview, 23 were excluded owing to missing information at the end-point, leaving 438 patients included for further analyses.

\section{Generalised anxiety disorder}

Three months after the index myocardial infarction, 24 patients (5.5\%) met the criteria for generalised anxiety disorder. Patients with generalised anxiety disorder were less likely to be treated with percutaneous transluminal coronary angioplasty $(P=0.03)$ and more likely to have a history of myocardial infarction $(P=0.02)$ compared with patients without generalised anxiety disorder. Of the patients with generalised anxiety disorder, $12(50 \%)$ had a concurrent depressive episode (Table 1).

During follow-up, 15 patients (62.5\%) with generalised anxiety disorder had a cardiovascular event or died compared with 183 patients $(44.2 \%)$ without generalised anxiety disorder (Fig. 1).

\section{Predictors of cardiovascular events and mortality}

During the follow-up period, 198 patients met the combined endpoint of all-cause mortality and cardiovascular events with a mean (standard deviation) follow-up period of 5.7 (3.1) years. Patients who had an event during the follow-up period were more likely to be older $(P<0.001)$, living alone $(P=0.04)$, to have an anterior myocardial infarction $(P=0.02)$, a LVEF lower than 40 $(P<0.001)$, and a history of myocardial infarction $(P=0.001)$, cerebrovascular disease $(P=0.01)$ and peripheral vascular disease $(P<0.001)$ (Table 2).

\section{Generalised anxiety disorder as a predictor of cardiovascular events and mortality}

Table 3 shows the association of generalised anxiety disorder with adverse prognosis for different models. Generalised anxiety disorder was associated with cardiovascular events and mortality after adjustment for age and gender (Fig. 2).

After additional adjustment for LVEF, generalised anxiety disorder remained an independent predictor of adverse outcome. Left ventricular ejection fraction (hazard ratio (HR) 1.58, 95\% confidence interval (CI) 1.17-2.14; $P=0.003$ ) and age (HR per year $1.03,95 \%$ CI $1.02-1.04, P<0.001)$ were also significant predictors in this model. Adjustment for post-myocardial infarction depression did not affect the association between generalised anxiety disorder and cardiovascular events and mortality. Post-myocardial infarction depression was not a 


\begin{tabular}{|c|c|c|c|}
\hline & $\begin{array}{l}\text { No generalised anxiety disorder } \\
\qquad(n=414)\end{array}$ & $\begin{array}{l}\text { Generalised anxiety disorder } \\
\qquad(n=24)\end{array}$ & $P$ \\
\hline Age, years: mean (s.d.) & $60.7(11.4)$ & $58.3(10.9)$ & 0.33 \\
\hline Male, $n(\%)$ & $334(80.7)$ & $20(83.3)$ & 0.75 \\
\hline Primary school only, $n$ (\%) & $78(18.8)$ & $6(25.0)$ & 0.46 \\
\hline Living alone, $n$ (\%) & $58(14.0)$ & $5(20.8)$ & 0.35 \\
\hline Current smoking, $n(\%)$ & $194(51.3)$ & $14(63.6)$ & 0.26 \\
\hline Left ventricular ejection fraction $<40, n(\%)$ & $97(23.5)$ & $7(29.2)$ & 0.53 \\
\hline Anterior site of myocardial infarction, $n$ (\%) & $130(31.4)$ & $8(33.3)$ & 0.84 \\
\hline Percutaneous transluminal coronary angioplasty, $n(\%)$ & $100(26.3)$ & $1(4.8)$ & 0.03 \\
\hline Coronary artery bypass graft, $n(\%)$ & $12(3.2)$ & $2(9.5)$ & 0.12 \\
\hline Killip class $\geqslant 2, n(\%)$ & $13(3.2)$ & $2(8.3)$ & 0.18 \\
\hline Creatinine phosphokinase-MB, ${ }^{\mathrm{b}}$ mean (s.d.) & $117.8(122.9)$ & $121.7(182.2)$ & 0.16 \\
\hline Creatinine phosphokinase, ${ }^{\mathrm{b}}$ mean (s.d.) & $1322.8(1319.2)$ & $1818.9(3010.8)$ & 0.48 \\
\hline History of myocardial infarction, $n$ (\%) & $53(12.8)$ & $7(29.2)$ & 0.02 \\
\hline History of cerebral vascular disease, $n(\%)$ & $18(4.3)$ & $1(4.2)$ & 0.97 \\
\hline History of peripheral vascular disease, $n(\%)$ & $27(6.5)$ & $3(12.5)$ & 0.26 \\
\hline Family history of cardiovascular disease, $n(\%)$ & $155(37.4)$ & $9(37.5)$ & 1.00 \\
\hline Diabetes, $n$ (\%) & $37(8.9)$ & $4(16.7)$ & 0.21 \\
\hline Hypertension, $n(\%)$ & $118(28.5)$ & $3(12.5)$ & 0.09 \\
\hline Hypercholesterolaemia, $n$ (\%) & $144(34.8)$ & $7(29.2)$ & 0.57 \\
\hline Body mass index, mean (s.d.) & $26.7(4.0)$ & $26.8(4.1)$ & 0.92 \\
\hline
\end{tabular}

significant predictor of adverse outcome in this model $(\mathrm{HR}=1.20$, 95\% CI 0.80-1.80; $P=0.38)$.

In sensitivity analyses, in addition to age and gender, consecutive adjustment for history of myocardial infarction, history of peripheral vascular disease, and anterior site of the index myocardial infarction did not materially affect the association between generalised anxiety disorder and adverse prognosis (Table 3 ).

\section{Discussion}

This study is the first to assess the prognostic impact of a diagnosis of current generalised anxiety disorder following myocardial infarction on cardiovascular events and all-cause mortality up until 10 years after the myocardial infarction. Patients with generalised anxiety disorder were at an almost twofold increased

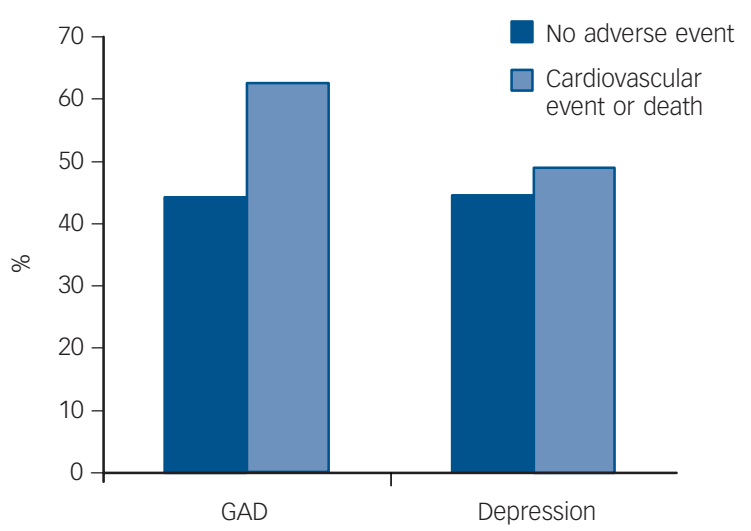

Fig. 1 Percentage of cardiac events and all-cause mortality in patients with $v$. without generalised anxiety disorder (GAD) and patients with $v$. without depression. risk of adverse prognosis after adjustment for age, gender and several cardiac disease severity parameters. Our findings are in concordance with those of other studies that investigated the impact of generalised anxiety disorder in patients with stable heart disease. ${ }^{13,19}$ In the present study, adjustment for depression did not influence the association of generalised anxiety disorder with adverse prognosis. This is consistent with other studies assessing the association between anxiety and cardiovascular events independent from depression. ${ }^{19,31}$

\section{Potential mechanisms}

Several potential biological mechanisms might explain the association between generalised anxiety disorder and coronary heart disease. For instance, several studies found a relationship

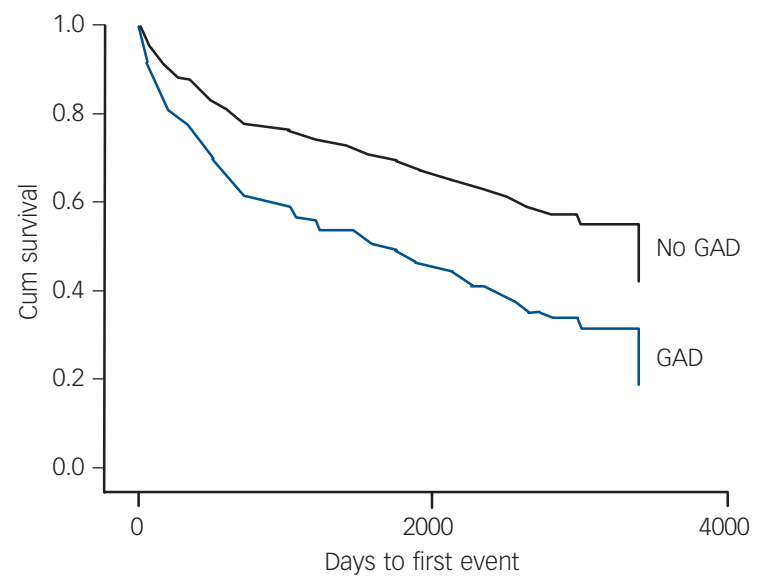

Fig. 2 The association of generalised anxiety disorder (GAD) after myocardial infarction with cardiac events and all-cause mortality adjusted for age and gender. 


\begin{tabular}{|c|c|c|c|c|}
\hline & Total sample $(n=438)$ & Event-free $(n=240)$ & Adverse event $(n=198)$ & $P$ \\
\hline Age, years: mean (s.d.) & $61(11.4)$ & $58(10.8)$ & $63(11.5)$ & $<0.001$ \\
\hline Male, $n$ (\%) & $354(80.8)$ & $198(82.5)$ & $156(78.8)$ & 0.33 \\
\hline Primary school only, $n$ (\%) & $84(19.2)$ & $42(17.5)$ & $42(21.2)$ & 0.33 \\
\hline Living alone, $n$ (\%) & $63(14.4)$ & $27(11.3)$ & $36(18.2)$ & 0.04 \\
\hline Current smoking, $n(\%)$ & $208(52.0)$ & $114(51.1)$ & $94(53.1)$ & 0.69 \\
\hline Left ventricular ejection fraction $<40, n(\%)$ & $104(23.8)$ & $40(16.7)$ & $64(32.5)$ & $<0.001$ \\
\hline Anterior site of myocardial infarction, $n(\%)$ & $138(31.5)$ & $64(26.7)$ & $74(37.4)$ & 0.02 \\
\hline Percutaneous transluminal coronary angioplasty, n (\%) & $101(25.2)$ & $61(27.4)$ & $40(22.5)$ & 0.26 \\
\hline Coronary artery bypass graft, $n$ (\%) & $14(3.5)$ & $10(4.5)$ & $4(2.2)$ & 0.23 \\
\hline Killip class $2, n(\%)$ & $15(3.4)$ & $6(2.5)$ & $9(4.6)$ & 0.24 \\
\hline Creatinine phosphokinase-MB, ${ }^{\mathrm{b}}$ mean (s.d.) & $118.0(126.6)$ & $117.9(132.0)$ & $118.1(119.9)$ & 0.75 \\
\hline Creatinine phosphokinase, ${ }^{b}$ mean (s.d.) & $1350.0(1461.0)$ & $1347.2(1523.8)$ & $1353.3(1384.9)$ & 0.70 \\
\hline History of myocardial infarction, $n$ (\%) & $60(13.7)$ & $21(8.8)$ & $39(19.7)$ & 0.001 \\
\hline History of cerebral vascular disease, $n$ (\%) & $19(4.3)$ & $5(2.1)$ & $14(7.1)$ & 0.01 \\
\hline History of peripheral vascular disease, $n(\%)$ & $30(6.8)$ & $7(2.9)$ & $23(11.6)$ & $<0.001$ \\
\hline Family history of cardiovascular disease, $n$ (\%) & $164(37.4)$ & 89 (37.1) & 75 (37.9) & 0.86 \\
\hline Diabetes, $n$ (\%) & $41(9.4)$ & $18(7.5)$ & $23(11.6)$ & 0.14 \\
\hline Hypertension, $n$ (\%) & $121(27.6)$ & $66(27.5)$ & $55(27.8)$ & 0.95 \\
\hline Hypercholesterolaemia, $n$ (\%) & $151(34.5)$ & $80(33.3)$ & $71(35.9)$ & 0.58 \\
\hline Body mass index, mean (s.d.) & $26.7(4.0)$ & $26.7(4.5)$ & $26.7(3.3)$ & 0.98 \\
\hline Depression, $n$ (\%) & $65(14.8)$ & $33(13.8)$ & $32(16.2)$ & 0.48 \\
\hline Generalised anxiety disorder, $n$ (\%) & $24(5.5)$ & $9(3.8)$ & $15(7.6)$ & 0.08 \\
\hline
\end{tabular}

between anxiety and indicators of autonomic dysfunction in patients with myocardial infarction, including reduced heart variability $^{32}$ and reduced baroflex cardiac control. ${ }^{33}$ Anxiety is also associated with increased platelet activity $^{34}$ and markers of inflammation $^{35}$ in otherwise healthy individuals. Another mechanism that may explain the association between anxiety and coronary heart disease is unhealthy behaviour, such as physical inactivity, an unhealthy diet and smoking. Anxiety is related to an unhealthy lifestyle in individuals at risk of coronary heart disease. ${ }^{36}$ In addition, anxiety following myocardial infarction is associated with lower adherence to various riskreducing recommendations such as smoking cessation. ${ }^{37,38}$ However, in a recent study, a variety of potential mediating mechanisms, including levels of cortisol and noradrenaline, heart rate variability, inflammation, smoking, medication nonadherence, and physical inactivity, could not explain the association between generalised anxiety disorder and cardiovascular events in patients with stable coronary heart disease. ${ }^{19}$ More research is needed to identify the mechanisms through which generalised anxiety disorder leads to an adverse prognosis.

Table 3 Association of generalised anxiety disorder with cardiac events and all-cause mortality

\begin{tabular}{|lcc|}
\hline Controlling for & $\begin{array}{c}\text { Hazard ratio } \\
(95 \% \mathrm{Cl})\end{array}$ & $P$ \\
\hline Age, gender & $1.94(1.14-3.30)$ & 0.01 \\
\hline Age, gender, left ventricular ejection fraction & $1.92(1.13-3.28)$ & 0.02 \\
\hline Age, gender, depression & $1.84(1.06-3.17)$ & 0.03 \\
\hline Age, gender, history of myocardial infarction & $1.81(1.06-3.09)$ & 0.03 \\
\hline $\begin{array}{l}\text { Age, gender, history of peripheral vascular } \\
\text { disease }\end{array}$ & $1.95(1.15-3.31)$ & 0.01 \\
\hline $\begin{array}{l}\text { Age, gender, anterior site of index } \\
\text { myocardial infarction }\end{array}$ & $1.89(1.11-3.22)$ & 0.02 \\
\hline
\end{tabular}

\section{Strengths and limitations}

A strength of the present study is the use of a standardised diagnostic interview to assess the presence of generalised anxiety disorder in this sample of patients with acute myocardial infarction. Other strengths are the long follow-up period and the objective and comprehensive assessment of cardiovascularrelated readmissions and mortality, resulting in a sufficient number of events. Limitations of this study are that we did not have information on the duration of the current generalised anxiety disorder period or information on whether patients were treated for generalised anxiety disorder or depression. In addition, we could not take the possible development of new generalised anxiety disorder or depressive episodes during the time frame of the follow-up period into account. Another limitation is the relatively small sample size, which limits our ability to adjust for potential covariates simultaneously. As a result of the relatively small sample size, we could not assess the impact of the comorbidity of generalised anxiety disorder and depression. It has been suggested that generalised anxiety disorder and depression might interact synergistically to affect cardiovascular mortality. ${ }^{10}$ However, in a study in patients with stable coronary heart disease, those with comorbid depression and generalised anxiety disorder were not at a greater risk of cardiovascular events compared with people with coronary heart disease with only depression or generalised anxiety disorder. ${ }^{13}$ Further, another large population study found that comorbid anxiety symptoms reduced mortality compared with depressive symptoms alone. ${ }^{39}$ Therefore, more research on the impact of comorbid anxiety and depression on the development and progression of coronary heart disease is warranted.

In our study, the association between generalised anxiety disorder and adverse prognosis could not be explained by several cardiac disease severity parameters, including LVEF and anterior site of the index myocardial infarction. However, it is still possible 
that the association is confounded by disease severity, especially since some symptoms of generalised anxiety disorder, such as palpitations and chest pain, might also be symptoms of heart disease. Further, patients with generalised anxiety disorder might worry about their health and be more likely to consult their doctor and be admitted to the hospital with cardiac complaints. This might explain part of the association between generalised anxiety disorder and cardiovascular-related hospital readmissions. To minimise this effect, we excluded hospital admissions for chest pain only from our analyses. Furthermore, although analyses on mortality separate from cardiovascular events were underpowered, the hazard ratio suggested an adverse effect of generalised anxiety disorder on mortality alone as well (data not shown).

\section{Clinical implications}

Although it has not been specifically studied in patients with heart disease, generalised anxiety disorder can be effectively treated with psychopharmacological treatment, for example selective serotonin reuptake inhibitors and serotonin noradrenaline reuptake inhibitors, and cognitive-behavioural therapy. ${ }^{40}$ Unfortunately, many patients do not receive adequate treatment. ${ }^{40}$ Besides the impact of anxiety on disability and decreased quality of life, clinicians should be aware of the finding that generalised anxiety disorder is associated with an increased risk of cardiovascular events and mortality following myocardial infarction.

\section{Funding}

The Depreml study was funded by the Netherlands Organization for Scientific Research (Zon MW, grant 904-57-100). P.J. and M.Z. are supported by a VIDI grant from the Dutch Medical Research Council (grant 016.086.397).

Annelieke M. Roest, PhD, Marij Zuidersma, PhD, Department of Psychiatry, University of Groningen, Groningen, The Netherlands; Peter de Jonge, PhD, Department of Psychiatry, University of Groningen, Groningen, and CORPS (Center of Research on Psychology in Somatic diseases), Department of Medical Psychology, Tilburg University, Tilburg, The Netherlands

Correspondence: Peter de Jonge, Department of Psychiatry, Hanzeplein 1, 9713 GZ, Groningen, The Netherlands. Email p.de.jonge@med.umcg.nl

First received 11 May 2011, final revision 22 Sep 2011, accepted 11 Nov 2011

\section{References}

1 Wulsin LR, Singal BM. Do depressive symptoms increase the risk for the onset of coronary disease? A systematic quantitative review. Psychosom Med 2003; 65: 201-10.

2 Van der Kooy $\mathrm{K}$, van Hout $\mathrm{H}$, Marwijk $\mathrm{H}$, Marten $\mathrm{H}$, Stehouwer $\mathrm{C}$, Beekman A. Depression and the risk for cardiovascular diseases: systematic review and meta analysis. Int J Geriatr Psychiatry 2007; 22: 613-26.

3 Nicholson A, Kuper H, Hemingway $H$. Depression as an aetiologic and prognostic factor in coronary heart disease: a meta-analysis of 6362 events among 146538 participants in 54 observational studies. Eur Heart J 2006; 27 2763-74.

4 Van Melle JP, De Jonge P, Spijkerman TA, Tijssen JG, Ormel J, van Veldhuisen DJ, et al. Prognostic association of depression following myocardial infarction with mortality and cardiovascular events: a meta-analysis. Psychosom Med 2004; 66: 814-22.

5 Barth J, Schumacher M, Herrmann-Lingen C. Depression as a risk factor for mortality in patients with coronary heart disease: a meta-analysis. Psychosom Med 2004; 66: 802-13.

6 Meijer A, Conradi HJ, Bos EH, Thombs BD, van Melle JP, de Jonge P. Prognostic association of depression following myocardial infarction and cardiovascular events: a meta-analysis of 25 years of research. Gen Hosp Psychiatry 2011; 33: 203-16.

7 Roest AM, Martens EJ, de Jonge P, Denollet J. Anxiety and risk of incident coronary heart disease. J Am Coll Cardiol 2010; 56: 38-46.
8 Janszky I, Ahnve S, Lundberg I, Hemmingsson T. Early-onset depression, anxiety, and risk of subsequent coronary heart disease: 37-year follow-up of 49,321 young Swedish men. J Am Coll Cardiol 2010; 56: 31-7.

9 Van Hout HPJ, Beekman ATF, de Beurs E, Comijs $\mathrm{H}$, van Marwijk $\mathrm{H}$ de Haan $\mathrm{M}$, et al. Anxiety and the risk of death in older men and women Br J Psychiatry 2004; 185: 399-404.

10 Phillips AC, Batty GD, Gale CR, Deary IJ, Osborn D, MacIntyre K, et al. Generalized anxiety disorder, major depressive disorder, and their commorbidity as predictors of all-cause and cardiovascular mortality: the Vietnam experience study. Psychosom Med 2009; 71: 395-403.

11 Holwerda TJ, Schoevers RA, Dekker J, Deeg DJ, Jonker C, Beekman AT. The relationship between generalized anxiety disorder, depression and mortality in old age. Int J Geriatr Psychiatry 2007; 22: 241-9.

12 Roest AM, Martens EJ, Denollet J, de Jonge P. Prognostic association of anxiety post myocardial infarction with mortality and new cardiac events: a meta-analysis. Psychosom Med 2010; 72: 563-9.

13 Frasure-Smith $\mathrm{N}$, Lespérance $\mathrm{F}$. Depression and anxiety as predictors of 2-year cardiac events in patients with stable coronary artery disease Arch Gen Psychiatry 2008; 65: 62-71.

14 Brennan C, Worrall-Davies A, McMillan D, Gilbody S, House A. The Hospital Anxiety and Depression Scale: a diagnostic meta-analysis of case-finding ability. J Psychosom Res 2010; 69: 371-8.

15 Kroenke K, Spitzer RL, Williams JB, Monahan PO, Löwe B. Anxiety disorders in primary care: prevalence, impairment, comorbidity, and detection. Ann Intern Med 2007; 146: 317-25.

16 Kroenke K, Spitzer RL, Williams JB, Löwe B. The Patient Health Questionnaire Somatic, Anxiety, and Depressive Symptom Scales: a systematic review. Gen Hosp Psychiatry 2010; 32: 345-59.

17 Balon R. Measuring anxiety: are we getting what we need? Depress Anxiety 2005; 22: 1-10.

18 Beuke CJ, Fischer R, McDowall J. Anxiety and depression: why and how to measure their separate effects. Clin Psychol Rev 2003; 23: 831-48.

19 Martens EJ, de Jonge $\mathrm{P}, \mathrm{Na} B$, Cohen BE, Lett $\mathrm{H}$, Whooley MA. Scared to death? Generalized anxiety disorder and cardiovascular events in patients with stable coronary heart disease. Arch Gen Psychiatry 2010; 67: 750-8.

20 Parker GB, Owen CA, Brotchie HL, Hyett MP. The impact of differing anxiety disorders on outcome following an acute coronary syndrome: time to start worrying? Depress Anxiety 2010; 27: 302-9.

21 Krueger RF. The structure of common mental disorders. Arch Gen Psychiatry 1999; 56: 921-6.

22 Vollebergh WA, ledema J, Bijl RV, de Graaf R, Smit F, Ormel J. The structure and stability of common mental disorders: the NEMESIS study. Arch Gen Psychiatry 2001; 58: 597-603.

23 Lamers $F$, van oppen $P$, Comijs $\mathrm{HC}$, Smit JH, Spinhoven $\mathrm{P}$, van Balkom AJ et al. Comorbidity patterns of anxiety and depressive disorders in a large cohort study: the Netherlands Study of Depression and Anxiety (NESDA). J Clin Psychiatry 2011; 72: 341-8.

24 Spijkerman $T$, de Jonge $\mathrm{P}$, van den Brink RH, Jansen JH, May JF, Crijns $\mathrm{HJ}$, et al. Depression following myocardial infarction: first-ever versus ongoing and recurrent episodes. Gen Hosp Psychiatry 2005; 27: 411-7.

25 Spijkerman TA, van den Brink RH, Jansen JH, Crijns HJ, Ormel J. Who is at risk of post-myocardial infarction depressive symptoms? J Psychosom Res 2005; 58: $425-32$

26 Spijkerman TA, van den Brink RH, May JF, Winter JB, van Melle JP de Jonge $P$, et al. Decreased impact of post-myocardial infarction depression on cardiac prognosis? J Psychosom Res 2006; 61: 493-9.

27 Kaptein $\mathrm{KI}$, de Jonge $\mathrm{P}$, van den Brink $\mathrm{RH}$, Korf J. Course of depressive symptoms after myocardial infarction and cardiac prognosis: a latent class analysis. Psychosom Med 2006; 68: 662-8.

28 de Jonge $P$, van den Brink RH, Spijkerman TA, Ormel J. Only incident depressive episodes after myocardial infarction are associated with new caridovascular events. J Am Coll Cardiol 2006; 48: 2204-8.

29 World Health Organization. The ICD-10 Classification of Mental and Behavioral Disorders: Diagnostic Criteria for Research. WHO, 1993.

30 Wittchen $\mathrm{H}-\mathrm{U}$. Reliability and validity studies of the WHO-Composite International Diagnostic Interview (CIDI): a critical review. J Psychiatr Res 1994; 28: $57-84$

31 Strik JJMH, Denollet J, Lousberg R, Honig A. Comparing symptoms of depression and anxiety as predictors of cardiac events and increased health care consumption after myocardial infarction. J Am Coll Cardiol 2003; 42: $1801-7$.

32 Martens EJ, Nyklícek I, Szsabó BM, Kupper N. Depression and anxiety as predictors of heart rate variability after myocardial infarction. Psychol Med 2008; 38: 375-83 
33 Watkins LL, Blumenthal JA, Carney RM. Association of anxiety with reduced baroreflex cardiac control in patients after acute myocardial infarction. Am Heart J 2002; 143: 460-6.

34 Cameron OG, Smith CB, Lee MA, Hollingsworth PJ, Hill EM, Curtis GC. Adrenergic status in anxiety disorders: platelet alpha 2-adrenergic receptor binding, blood pressure, pulse, and plasma catecholamines in panic and generalized anxiety disorder patients and in normal subjects. Biol Psychiatry 1990; 28: 3-20.

35 Pitsavos C, Panagiotakos DB, Papageorgiou C, Tsetsekou E, Soldatos C Stefanadis $C$. Anxiety in relation to inflammation and coagulation markers, among healthy adults: the ATTICA study. Atherosclerosis 2006; 185: 320-6.

36 Bonnet F, Irving K, Terra JL, Nony P, Berthezène F, Moulin P. Anxiety and depression are associated with unhealthy lifestyle in patients at risk of cardiovascular disease. Atherosclerosis 2005; 178: 339-44.
37 Benninghoven $D$, Kaduk A, Wiegand $U$, Specht T, Kunzendorf S, Jantschek G. Influence of anxiety on the course of heart disease after acute myocardial infarction - risk factor or protective function? Psychother Psychosom 2006 75: $56-61$.

38 Kuhl EA, Fauerbach JA, Bush DE, Ziegelstein RC. Relation of anxiety and adherence to risk-reducing recommendations following myocardial infarction. Am J Cardiol 2009; 103: 1629-34.

39 Mykletun A, Bjerkeset O, Øverland S, Prince M, Dewey M, Stewart R. Levels of anxiety and depression as predictors of mortality: the HUNT study. Br J Psychiatry 2009; 195:118-25.

40 Davidson JR. First-line pharmacotherapy approaches for generalized anxiety disorder. J Clin Psychiatry 2009; 70: 25-31.

\section{The diet of King George III}

\section{Rafael Euba}

The following are extracts from an article in The Times, entitled 'On His Majesty's Disorder'. It was published in November 1788, at the height of the worst episode in King George III's mental illness. The writer ('Brit. et Pat. Amicus') addresses his bitter criticism of the treatment the King is receiving to Sir George Baker MD, His Majesty's physician. Capital letters, italics and some archaic spellings are reproduced here as they appear in the original text.

(. . .) Great care, Sir George, must be taken to remedy a violent disorder when it is once got into the head and to prevent the delirium which occations [sic] a temporary alienation of the mind and may (but God forbid it) produce a fixed frenzy in the brain, so difficult it is to be dislodged. A dreadful event! And yet it would be cruel to call it INSANITY, since it is not a natural incapacity of the mind, but one unhappily acquired by perhaps too much confidence in the faculty.

(. . ) Sir George, if the nation, in their anxiety and solicitude for their Sovereign, see, with astonishment and concern, the treatment of His Majesty's disorder, by which a life most dear to his subjects and most important to Europe, has been endangered, what will they think of so strange a regimen?

'Tea', which has no virtue, 'Bread and Butter,' which has little nourishment, and 'Potatoes', fit only for animals, offer together a specimen of the sagacity of the faculty.

Without enquiring whether the King's disorder is natural or acquired - that is, whether the FEVER is the cause of his complaint or the effect of his treatment, I will venture to pronounce that, in the present situation of the Royal Patient, weak coffee is better for the bowels, that have been greatly disorder by a violent cold, than nervous and windy tea - that soft toast and butter is more nourishing and proper than bread and butter - and that bread pudding, or batter pudding, or ground rice pudding, the former in particular, is light, nourishing, and infinitely better than 'potatoe-pudding.

Sir George, would not a little boiled chicken, a little boiled veal, and weak veal broth, with a little wine and water occasionally, be a better diet than the rubbish we are told is prescribed by his Majesty's physicians? (. . . )

For God's sake, Sir George, if the faculty did not know how to treat the disorder of a Prince with an excellent constitution, and the best habits of body and mind, without endangering his valuable life, let the world see that you have, at least, sense enough to know when it is supposed he is recovering from so great a danger, what it is wholesome and good for his Majesty to eat.

The Times, 29 November 1788. 